J. MED. MICROBiOL. - VOL. 16 (1983), 417-426

(C) 1983 The Pathological Society of Great Britain and Ireland

\title{
SERUM IgA ANTIBODY TO BORDETELLA PERTUSSIS AS AN INDICATOR OF INFECTION
}

\author{
J. NAGel AND E. J. PoOT-SChOltens
}

Laboratory for Immunochemistry, Rijksinstituut voor de Volksgezondheid, P.O. Box 1,
3720 BA Bilthoven, The Netherlands

\begin{abstract}
SUMmaRY. The levels of pertussis-specific IgA antibodies in sera from vaccinees and from children with Bordetella pertussis infection were compared by an enzyme-linked immunosorbent assay (ELISA). Serum IgA antibodies were produced only after natural contact with the pathogen and, therefore, their presence can be used as an indicator of infection. However, in view of the relatively long interval between infection and the appearance of antibodies, and the prolonged antibody response, their presence cannot be used as proof of recent infection. The finding of these antibodies in a high percentage of the normal adult population may indicate a constant circulation of $B$. pertussis without symptoms of disease.
\end{abstract}

\section{INTRODUCTION}

Infection with Bordetella pertussis results in an exclusively local multiplication of the bacteria in association with the ciliated epithelium of the respiratory tract, without dissemination to other sites (Olson, 1975; Linneman, 1979). However, products secreted by the bacteria enter the circulation and cause the typical symptoms of pertussis. Holt (1972) and Pittman (1979) have suggested that protection against pertussis may be at two levels: a local protection against the infection and a systemic immunity neutralizing the substances secreted by the bacteria.

It has been found that several respiratory infections induce a local as well as a systemic immune response (Waldman and Ganguly, 1974; Bienenstock and Befus, 1980; Ogra, Fishaut and Gallagher, 1980); B. pertussis is no exception. Serum antibodies can be demonstrated readily by various techniques. A local immune response in humans and in experimental animals has been proved by detection of IgA antibodies in respiratory secretions (Geller and Pittman, 1973; Thomas, 1975; Aleksandrowicz and Pstragowska, 1980; Goodman, Wort and Jackson, 1981; Ashworth et al., 1982). Goodman and co-workers used the detection of IgA antibodies in nasopharyngeal secretions as an indicator of recent infection.

In a preliminary investigation, the isotype of circulating antibodies was investigated in an attempt to differentiate between antibodies induced by infection and those induced by vaccination. In agreement with others (Aleksandrowicz and 
Pstragowska, 1980; Ruuskanen, Mertsola and Viljanen, 1981; Granström et al., 1982; Viljanen et al., 1982) we found that serum IgA, IgM and IgG antibodies were induced by infection. However, in sera taken from infants after a full course of immunization, only IgM and IgG antibodies were detectable. Consequently the presence of serum $\operatorname{IgA}$ antibodies could be used as an indicator of a natural contact with $B$. pertussis or related bacteria. In this report, we present the results of our investigations of the levels of pertussis-specific IgA (PS-IgA) in the sera of children after natural infection or vaccination. Attention is paid to the time of appearance and the persistence of these antibodies. Furthermore, the level of IgA antibodies in a normal population has been studied and the possible origin of these antibodies is discussed.

\section{MATERIALS AND METHODS}

B. pertussis antigen solution. B. pertussis strain 114, obtained through the courtesy of Dr C. R. Manclark, Bureau of Biologics, FDA, Bethesda, MD, was grown in the medium of Sato, Arai and Suzuki (1974) in stationary culture. After 5 days, the culture was centrifuged and the cells were resuspended in $0.1 \mathrm{M}$ phosphate buffer, $p \mathrm{H} \mathrm{7.0}$, containing $0.5 \mathrm{M} \mathrm{NaCl}$ at a concentration of 400-500 International Opacity Units (IOU) by comparison with the WHO International Reference Preparation of Opacity (1975). After incubation for $2 \mathrm{~h}$ at $37^{\circ} \mathrm{C}$ and $15 \mathrm{~h}$ at $4^{\circ} \mathrm{C}$ the suspension was centrifuged and the supernate was diluted to a concentration equivalent to 15 IOU by the addition of saline. This antigen solution was used to coat microtitre plates for ELISA.

Anti-human IgA-HRP conjugate. A sheep was immunized by multiple injections of $1 \mathrm{mg}$ of purified IgA isolated from IgA myeloma serum (Rivat et al., 1977). The first injection was given in complete, the subsequent injections in incomplete Freund's Adjuvant (Difco Laboratories, MI).

The antiserum was rendered mono-specific by absorption with IgA-free human cord serum. The IgG fraction was conjugated with horseradish peroxidase (HRP, type IV, Sigma, USA) according to the methods of Nakane and Kawaoi (1974) but omitting the final $\mathrm{NaBH}_{4}$-reduction step (Hagenaars, Kuipers and Nagel, 1980). The optimal working dilution of the conjugate was 1 in 200.

Substrate solution. A solution of $80 \mathrm{mg}$ of 5-amino-2-hydroxybenzoic acid (Merck, FRG) in $100 \mathrm{ml}$ of distilled water was adjusted to $p \mathrm{H} 6.0$ with $\mathrm{NaOH}$. Immediately before use, $20 \mu \mathrm{l}$ of $\mathrm{H}_{2} \mathrm{O}_{2} 30 \%$ (v/v) solution (Merck, FRG) was added.

Reference preparation. A $4 \%(\mathrm{w} / \mathrm{v})$ anti-pertussis immunoglobulin solution was used as a reference preparation. It had been made from pooled sera collected from children who had been immunized with pertussis vaccine after their recovery from pertussis infection. The sera had been fractionated by alcohol precipitation 25 years ago and stored subsequently at $4{ }^{\circ} \mathrm{C}$ in the presence of Merthiolate $0.01 \%(\mathrm{w} / \mathrm{v})$. The preparation still contained a substantial amount of $\mathrm{IgA}, \mathrm{IgM}$ and IgG antibodies to $B$. pertussis.

Sera. Three collections of sera were tested: 1 . Sera taken from 48 infants aged 3 months, before their first pertussis vaccination, and from 39 children aged 13 months, one month after their fourth pertussis vaccination. The sera had been collected in 1975 as part of a study to test the efficacy of an adsorbed quintuple vaccine against diphtheria, tetanus, pertussis, poliomyelitis and measles. The pertussis component had a concentration of $16 \mathrm{IOU} / 1 \mathrm{ml}$ dose (Brouwer and Cohen, 1976). 2. Sera from infants and children diagnosed as pertussis cases. The samples were taken at varied times after the onset of symptoms. In some cases, more than one sample was available. Only children whose clinical diagnosis had been supported by culture of the pathogen or by haematological or serological findings, were included in this study. The haematological criteria of Lagergren (1963) were adopted: in children aged $<6$ months, a leukocytosis greater than $20 \times 10^{9} \mathrm{WBC} / \mathrm{L}$ or a lymphocyte count of at least $15 \times 10^{9} / \mathrm{L}$ is suggestive of pertussis infection; in older children the figures are $15 \times 10^{9} / \mathrm{L}$ and $11 \times 10^{9} / \mathrm{L}$, respectively. A four-fold rise of the bacterial agglutination titre or a single titre of 256 or greater were taken as serological evidence of infection. 3. Sera from individuals of both sexes of various 
ages. These were obtained by family doctors from people living in different parts of the country and not suffering from any infectious disease. The sera were collected as part of a surveillance study designed to test the immune status of the normal Dutch population over the age of 10 years.

ELISA. A micro-ELISA procedure was used in which flat-bottomed PVC microtitre plates (type III, Flow Laboratories, Scotland) were coated with the antigen solution $0.1 \mathrm{ml} /$ well by incubation at $4^{\circ} \mathrm{C}$ overnight. The plates were washed with Tween $800.01 \%(\mathrm{v} / \mathrm{v})$ in tap water before the addition of $0.1 \mathrm{ml}$ of the serum samples diluted 1 in 100 or of serial two-fold dilutions of the reference preparation (starting dilution 1 in 100). Each sample was tested in duplicate. After incubation at $37^{\circ} \mathrm{C}$ for another $2 \mathrm{~h}$ and further washing steps, $0.1 \mathrm{ml}$ of the optimal conjugate dilution was added and the plates were incubated at $37^{\circ} \mathrm{C}$ for $2 \mathrm{~h}$. After a third washing step, $0.1 \mathrm{ml}$ of the substrate solution was added and after standing for $20 \mathrm{~min}$ at room temperature the reaction was stopped by the addition of $0.1 \mathrm{ml}$ of $0.3 \mathrm{~N} \mathrm{NaOH}$ solution. The optical density was measured at $449 \mathrm{~nm}$ with a multichannel vertical pathway spectrophotometer (Titertek ${ }^{\star}$ Multiskan, Flow Laboratories, Scotland).

For each assay, a calibration curve was drawn after plotting the optical density values of the dilutions of the reference preparation against their respective concentrations. With the aid of this calibration curve the pertussis-specific IgA (PS-IgA) antibody content of a sample was expressed as a potency index, relative to the reference preparation, where a value of 100 means a sample equal in activity with the reference and, for example, a value of 1.5 means a sample with $1.5 \%$ of the potency of the reference. The lower limit detection of the assay was 1.5 .

Reproducibility of the ELISA. Over a 1-year period, several selected sera were tested repeatedly to study the inter-assay variability. Seven sera were assayed 13 times and 11 sera six times. For calculations, results lower than 1.5 were assumed to be 0.5 .

\section{RESULTS}

\section{Variability of ELISA results}

The reproducibility of the determination of PS-IgA antibodies by ELISA was studied. For each selected serum the standard deviation (SD) of the antibody levels in different assays was plotted against the mean value of these levels (fig. 1). It was deduced from the slope of the regression line that the SD of a single determination was about $0 \cdot 2$ times the actual IgA antibody level. However, for potency index values $<10$, a constant value for the SD equal to 1.6 (mean of four values, see fig. 1 ) was used to avoid an underestimation of the SD of a single determination. It was calculated that when two individual results, each higher than 10 differed by more than 0.55 times the mean value, this difference was statistically significant. For potency index values $<10$, the critical value was $4 \cdot 4$. A PS-IgA relative potency of $5 \cdot 0$ or higher was assumed to differ significantly from the lower detection limit of 1.5 .

\section{Pertussis-specific IgA antibody levels after vaccination}

Sera were obtained from infants before and after a full course of pertussis vaccination, at 3 and 13 months old respectively. None of the 48 sera collected before vaccination had detectable PS-IgA antibodies. Only one out of 39 sera collected after vaccination had a potency index, relative to the reference preparation, as high as $\mathbf{5 \cdot 0}$. All other sera contained lower concentrations of PS-IgA antibodies. For this reason, the relative potency index of 5.0 has been assumed to represent the maximum level of serum IgA antibodies that can be attained after pertussis vaccination. Taking into account the statistical consideration that values of 5.0 and higher differ significantly 


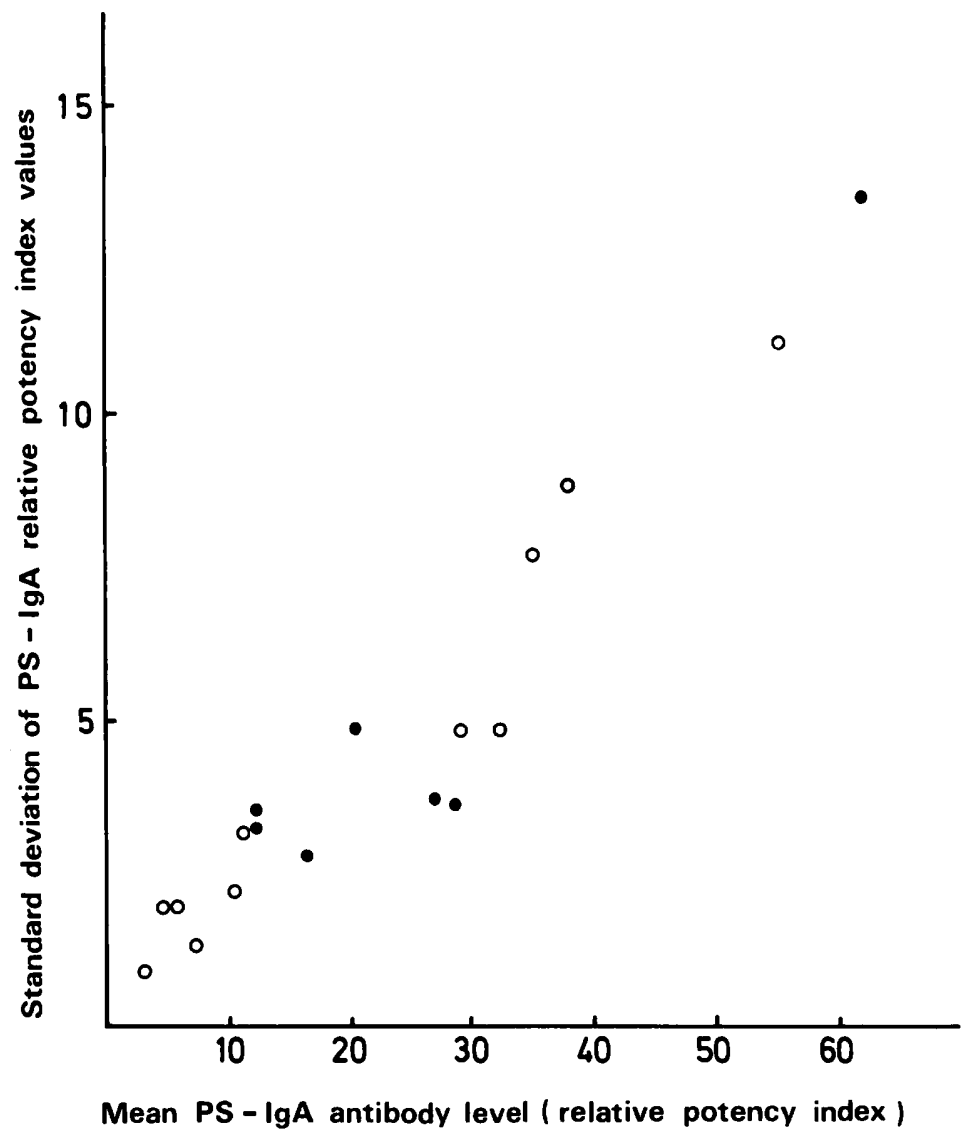

FIG. 1.-The relationship of the mean relative potency value for the PS-IgA antibody level to its standard deviation. $=$ sera tested 13 times; $0=$ sera tested 6 times.

from the lower detection limit of $1 \cdot 5$, one may conclude that serum PS-IgA normally will not be induced by parenteral immunization. Consequently, the presence of serum PS-IgA antibodies would indicate a natural contact with $B$. pertussis.

\section{Serum IgA antibody response after infection}

PS-IgA antibody levels were determined in sera from children in whom the clinical diagnosis of pertussis was supported by laboratory data. The sera were classified according to the age of the children at the time of onset of disease: $0-3$ months, 4-12 months, $1-4$ years, 5-10 years and $>10$ years. In table I the percentage of children having a PS-IgA relative potency of 5.0 or higher is given for each age-group. Additionally, the median of the highest relative PS-IgA antibody level found per child in each group is presented. The control groups consisted of healthy infants before their first vaccination aged 3 months, healthy children 1 month after their fourth vaccination aged 13 months and healthy, fully-vaccinated children aged 10-14 years. It is clear that in the groups of pertussis cases many more children had positive serum IgA antibody levels than in the corresponding groups of healthy children and the 
TABLE I

Pertussis-specific IgA antibody levels in sera taken from children diagnosed as pertussis cases and from healthy children of similar age

\begin{tabular}{l|ccc}
\hline & $\begin{array}{c}\text { Percentage of sera } \\
\text { with a PS-IgA rela- } \\
\text { tive potency } \\
\text { index* } \geqslant 5 \cdot 0\end{array}$ & $\begin{array}{c}\text { Median } \\
\text { PS-IgA } \\
\text { index }\end{array}$ & $\begin{array}{c}\text { Number of chil- } \\
\text { dren per group }\end{array}$ \\
Age-group & & & \\
PERTUSSIS CASES & 53 & 5 & 30 \\
0-3 months & 73 & 11 & 26 \\
4-12 months & 87 & 23 & 38 \\
1-4 years & 93 & 42 & 14 \\
5-10 years & 100 & 49 & 6 \\
>10 years & 0 & $<1.5$ & 48 \\
CONTROLS & & $<1.5$ & 39 \\
3 months & & & \\
(before vaccination) & 3 & $<1.5$ & 54 \\
13 months \\
(after vaccination)
\end{tabular}

* See Methods.

median values of the levels were higher. Moreover, in the older age-groups both parameters were higher than in the younger age-groups.

For each age-group and for each week of blood collection, the percentage of samples with a positive PS-IgA antibody level is given in table II. The day of onset of symptoms, as reported by the mother, has been taken as the first day of disease. From this table, it may be concluded that for infants younger than 1 year it will take approximately 6-7 weeks from the first day of disease for the serum PS-IgA antibody content to reach a relative potency index of 5.0. For older children, the period seems to be much shorter.

In children from whom more than one sample was available the change in the $\operatorname{IgA}$ antibody level during the course of disease was studied. The PS-IgA levels in samples taken about 8 weeks after the first day of disease were plotted against the values for the first available samples (fig. 2). In many, but not all cases, a significant rise in PS-IgA was observed, especially in the older age-groups. Table III shows that the IgA antibodies persisted for quite a long time, although the number of children from whom at least three samples were available was small.

TABLE II

Percentage of sera with positive pertussis-specific $\operatorname{IgA}$ levels at various times after the onset of pertussis symptoms

\begin{tabular}{l|cccccccccc}
\hline & \multicolumn{8}{|c}{ Percentage of positive sera* (number of sera tested) in week } \\
\cline { 2 - 10 } Age-groups & 1 & 2 & 3 & 4 & 5 & 6 & 7 & 8 & 9 & 10 \\
\hline $0-3$ months & $14(7)$ & $25(8)$ & $31(13)$ & $57(7)$ & $60(5)$ & $33(3)$ & $100(6)$ & $100(2)$ & $100(2)$ & $100(2)$ \\
$4-12$ months & $0(5)$ & $29(7)$ & $50(10)$ & $56(9)$ & $88(8)$ & $100(4)$ & $83(6)$ & $100(1)$ & $50(4)$ & $100(3)$ \\
$1-4$ years & $80(5)$ & $83(13)$ & $100(16)$ & $93(14)$ & $83(12)$ & $100(11)$ & $88(8)$ & $100(4)$ & $100(2)$ & $100(8)$ \\
$\geqslant 5$ years & $75(8)$ & $90(10)$ & $100(11)$ & $96(23)$ & $100(6)$ & $100(15)$ & $100(5)$ & $100(4)$ & $100(8)$ & $100(4)$ \\
\hline
\end{tabular}

* Sera with a PS-IgA potency index of $\geqslant 5 \cdot 0$ (see Methods). 

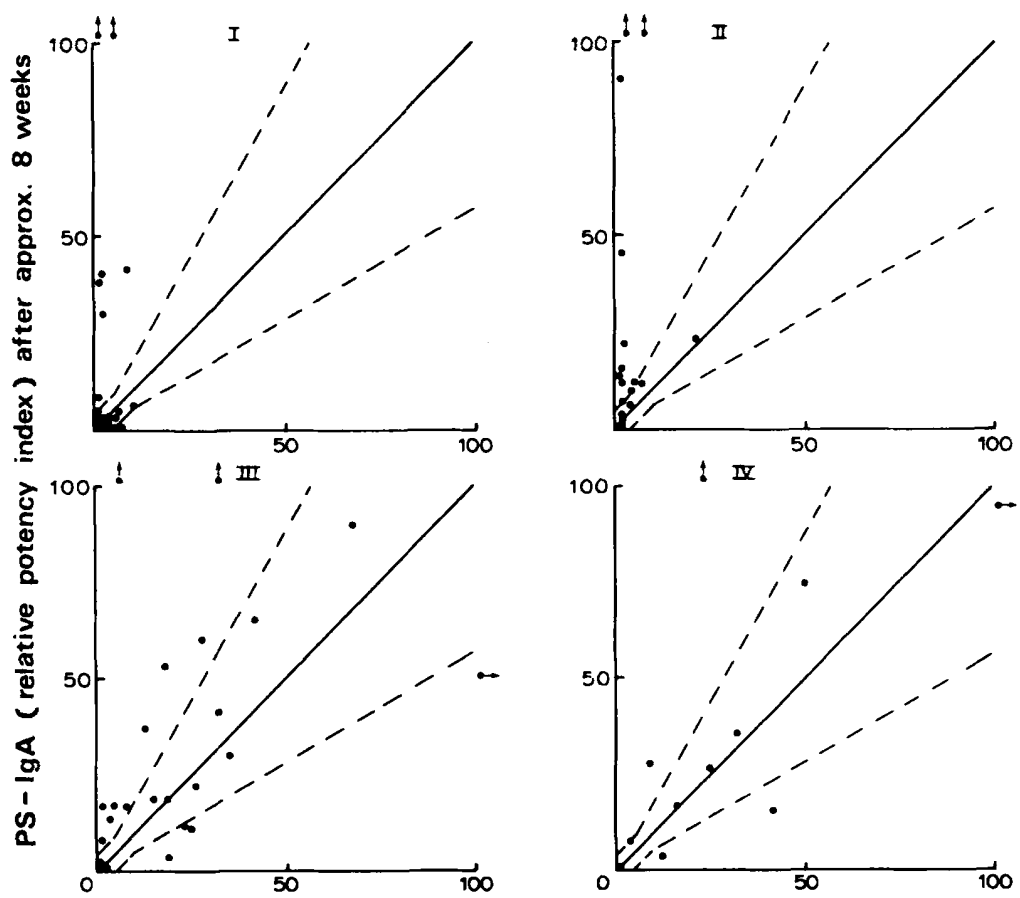

PS-IgA (relative potency index) in first available sample

FIG. 2.-The increase in serum PS-IgA antibody levels in the course of pertussis infection in children of different age-groups. I: 0-3 months; II: 4-12 months; III: $1-4$ years; IV: $>5$ years. Abscissa: antibody level in first available sample. Ordinate: antibody level in sample taken about 8 weeks after the onset of pertussis symptoms. $\rightarrow$ : PS-IgA potency index $>100 ; \longrightarrow$ : bisector; $-\cdot-$ : boundaries of regions of statistical significance $(p<0.05)$.

\section{Pertussis-specific IgA antibody levels in a normal Dutch population}

Table IV shows the results of the PS-IgA antibody determinations in sera from a surveillance study. The percentages of males and females with a positive IgA antibody level (relative potency index $\geqslant 5.0$ ) are given for each age-group. There was a gradual increase of positives in the older age-groups: only $15 \%$ of the males aged $10-14$ years were positive, whereas $>50 \%$ of those aged 20 years or older were positive. In addition, more males than females had positive IgA antibody levels. Consequently, the median values of the IgA antibody levels were generally higher in males than in females.

\section{Discussion}

The level of pertussis-specific serum IgA antibodies after natural infection and vaccination was studied by an enzyme-linked immunosorbent assay procedure. In agreement with the results obtained by Ruuskanen et al. (1980) we found that after a full course of parenteral immunization with pertussis vaccine only a low, negligible level of serum PS-IgA antibodies could be detected. One month after the fourth vaccination when the children were 13 months old, only one out of 39 children had a PS-IgA antibody level as high as $5 \%$ of that of the reference preparation (a relative 


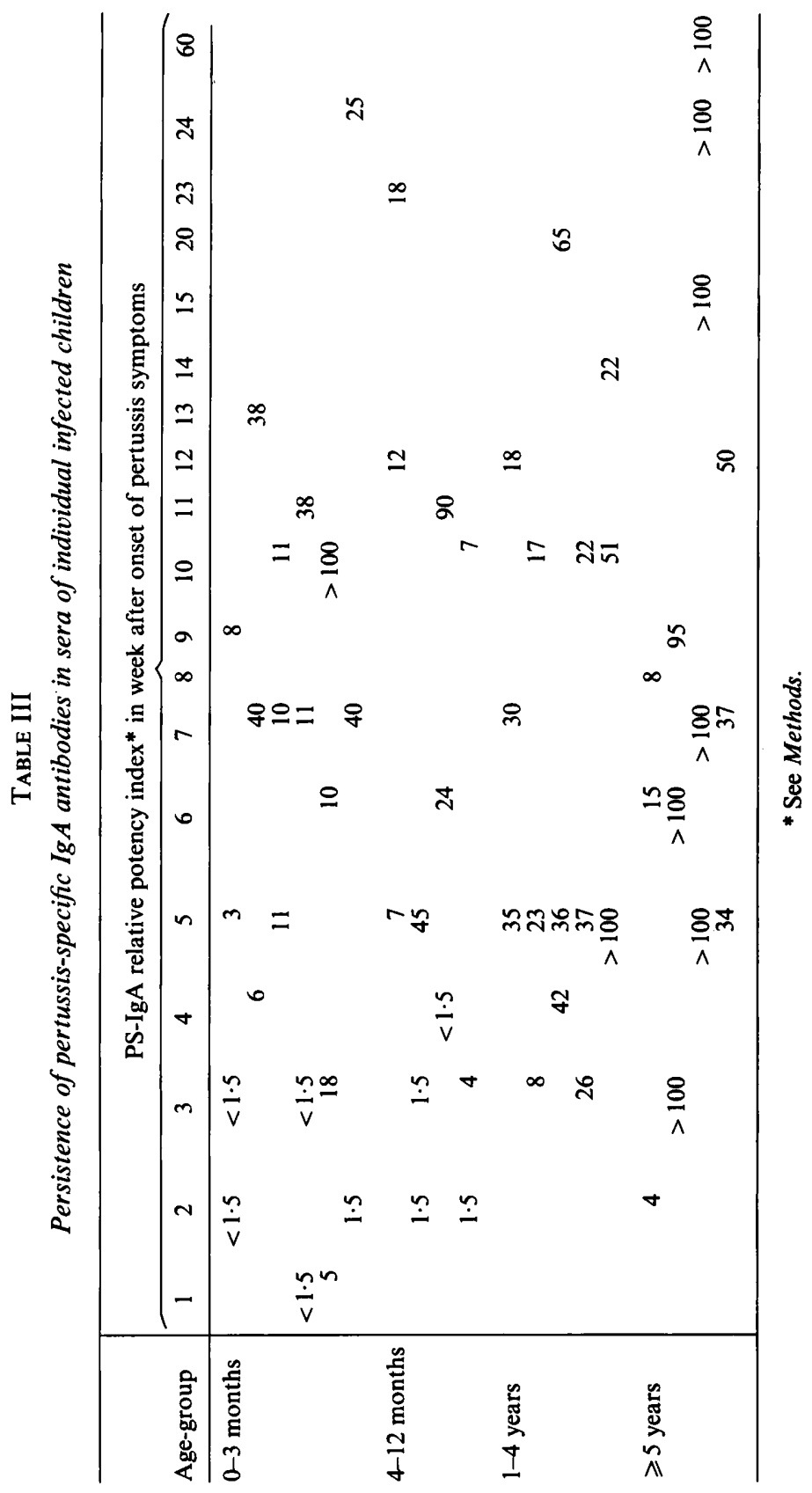


TABLE IV

Pertussis-specific IgA antibody levels in healthy people of different age-groups. In each age-group, 26-40 sera were tested

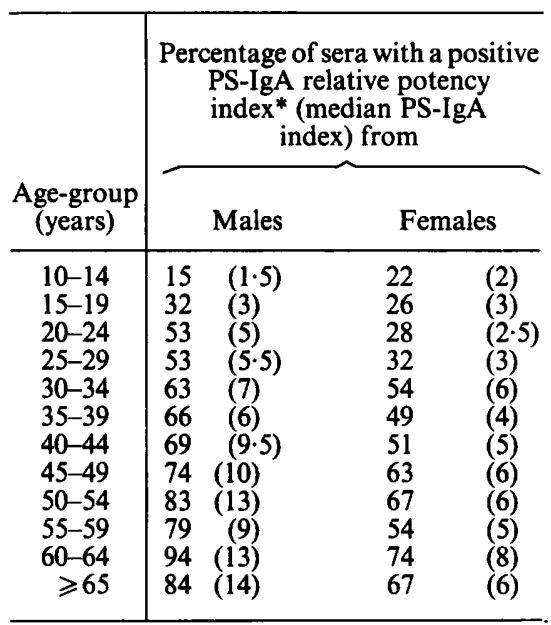

* See Methods.

potency index of $5 \cdot 0$ ). Thus, values of 5.0 or higher were assumed to be caused by natural contact with pertussis antigens. This hypothesis was supported by the observation that many more sera from children diagnosed as pertussis cases had PS-IgA relative potency index values $>5.0$ compared with sera from vaccinated, healthy children at corresponding ages. Moreover, the median PS-IgA levels in the groups of infected children were much higher than in the control groups, especially in the older age-groups. In some individuals, index values $>100$ were found.

In many cases, a significant increase in the serum PS-IgA antibody level in the course of the disease was observed although in many other cases no significant change was found, even when $B$. pertussis had been isolated. In a few cases a decrease was found. Two possible explanations for such insignificant responses may be mentioned: first, the high level of antibodies sometimes found in the first sample may indicate that the stage of disease was later than reported and second, the age of the child at the time of infection may be important. Serum IgA cannot cross the placenta (Heremans, 1974) and only trace amounts of $\operatorname{IgA}$ are present in the blood of the new-born. The production of IgA by the child develops slowly and although IgA may be transferred from mother to child by colostrum, the adult level is reached only in adolescence. However, in sera from non-infected infants aged 3 months, PS-IgA antibodies were not found, indicating that at this age maternal antibodies do not interfere (table I).

Although the presence of PS-IgA antibodies indicates infection with $B$. pertussis or related organisms, the test can only be used for retrospective confirmation of the clinical diagnosis. Table II shows that it took approximately 6-7 weeks from the first day of disease for the relative potency index in almost all sera of children $<1$ year to exceed a value of 5.0. In the older age-groups this period was shorter, which may result from more efficient IgA antibody production in this group.

More data are required to establish the stability of the IgA antibody level. From table III it may be concluded that persistence of the serum IgA antibodies is common 
and independent of the age of the child. This phenomenon might explain the high percentage of healthy adults who had PS-IgA index values $>5.0$. In the Netherlands mass pertussis vaccination started in 1953 and it could be inferred that vaccination afforded substantial protection against the disease because a lower percentage of individuals born after 1953 (the first three age-groups in table IV) appear to have been infected compared with those born before 1950 (age-group 30-34 and higher). However, the fact that females seem to be more susceptible to the disease than males (Olson, 1975) militates against this hypothesis because more males than females had positive levels of IgA antibodies. Moreover, such a long persistence of antibodies seems unlikely without frequent stimulation of the immune system. It is suggested, therefore, that the presence of $\operatorname{IgA}$ antibodies indicates a circulation of $B$. pertussis or related organisms amongst the adult population, producing only asymptomatic infections (Linneman, 1979).

The results described in this paper demonstrate that the presence of specific circulating IgA antibodies to pertussis antigens can be used as a reliable indicator of a natural infection with $B$. pertussis. However, the application to sero-diagnosis of acute infections is of less immediate value in view of the delayed production, especially in infants, and subsequent persistence of these antibodies.

The authors thank Dr V. M. Sekhuis for his statistical advice and the World Health Organization for financial support to this study (B3/181/10D).

\section{REFERENCES}

AleksandrowiCZ, J. AND PstragowsKa, W. 1980. Biological activity of serum and secretory IgA in the course of pertussis in children. Medycyna Doswiadczalna i Mikrobiologia, 32, 201-207. (in Polish).

Ashworth, L. A. E., Fitzgeorge, R. B., Irons, L. I., Morgan, C. P. and Robinson, A. 1982. Rabbit nasopharyngeal colonization by Bordetella pertussis: the effects of immunization clearance and on serum and nasal antibody levels. Journal of Hygiene, 88, 475-486.

Bienenstock, J. AND Befus, A. D. 1980. Mucosal immunology. Immunology, 41, 249-270.

BROUWER, R. AND COHEN, H. 1976. Reactogenicity for infants of pertussis vaccines, harvested by centrifugation or acid precipitation. Journal of Biological Standardization, 4, 5-12.

GelleR, B. D. AND PITTMAN, M. 1973. Immunoglobulin and histamine-sensitivity response of mice to live Bordetella pertussis. Infection and Immunity, 8, 83-90.

GoOdMAN, Y. E., WORT, A. J. AND JACKSON, F. L. 1981. Enzyme-linked immunosorbent assay for detection of pertussis immunoglobulin $\mathrm{A}$ in nasopharyngeal secretions as an indicator of recent infection. Journal of Clinical Microbiology, 13, 286-292.

Granström, M., Lindberg, A. A., AskelöF, P. and Hederstedt, B. 1982. Detection of antibodies in human serum against the fimbrial haemagglutinin of Bordetella pertussis by enzyme-linked immunosorbent assay. Journal of Medical Microbiology, 15, 85-96.

HagenaArs, A. M., Kuipers, A. J. AND Nagel, J. 1980. Preparation of enzyme-antibody conjugates. In Immunoenzymatic assay techniques, edited by R. Malvano, Martinus Nijhoff, The Hague. pp. 16-27.

Heremans, J. F. 1974. Immunoglobulin A. In The Antigens, Vol. II, edited by M. Sela, Academic Press, New York. pp. 365-522.

Holt, L. B. 1972. The pathology and immunology of Bordetella pertussis infection. Journal of Medical Microbiology, 5, 407-424.

LAGERGREN, J. 1963. The white blood cell count and the erythrocyte sedimentation rate in pertussis. Acta Paediatrica, 52, 405-409.

Linneman, C. C. 1979 . Host-parasite interactions in pertussis. In Proceedings of the 3rd International Symposium on Pertussis, held in 1978, edited by C. R. Manclark and J. C. 
Hill, U.S. Department of Health, Education and Welfare, Bethesda, MD, DHEW Publication No. (NIH) 79-1830, pp. 3-18.

NAKANE, P. K. AND KAWAOI, A. 1974. Peroxidase-labeled antibody. A new method of conjugation. Journal of Histochemistry and Cytochemistry, 22, 1084-1091.

Ogra, P. L., Fishaut, M. AND Gallagher, M. R. 1980. Viral vaccination via the mucosal routes. Reviews of Infectious Diseases, 2, 352-369.

Olson, L. C. 1975. Pertussis. Medicine, 54, 427-469.

Pittman, M. 1979. Pertussis toxin: The cause of the harmful effects and prolonged immunity of whooping cough. A hypothesis. Reviews of Infectious Diseases, 1, 401-412.

Rivat, C., Bourguignon, J., Fontaine, M. and Ropartz, C. 1977. Enzymatic fragmentation of human $\operatorname{IgA~} \mathrm{F}(\mathrm{abc})^{\prime 2}$ : a new peptic fragment. Immunochemistry, 14, 69-73.

RuUsKanen, O., Mertsola, J. AND Viljanen, M. K. 1981. Atypical whooping cough: serological diagnosis and clinical signs. Pediatric Research, 15, 1185.

Ruuskanen, O., Viljanen, M. K., Salmi, T. T., Lehtonen, O.-P., Kouvalainen, K. and Peltonen, T. 1980. DTP and DTP-inactivated polio vaccines: Comparison of adverse reactions and IgG, IgM and IgA antibody responses to DTP. Acta Paediatrica Scandinavica, 69, 177-182.

Sato, Y., ARAI, H. AND SuzuKI, K. 1974. Leukocytosis-promoting factor of Bordetella pertussis. III. Its identity with protective antigen. Infection and Immunity, 9, 801-810.

ThомAS, G. 1975. Respiratory and humoral immune response to aerosol and intramuscular pertussis vaccine. Journal of Hygiene, 74, 233-237.

Viluanen, M. K., RuUSKanen, O., GRAnberg, C. and Salmi, T. T. 1982. Serological diagnosis of pertussis: IgM, IgA and IgG antibodies against Bordetella pertussis measured by enzyme-linked immunosorbent assay (ELISA). Scandinavian Journal of Infectious Diseases, 14, 117-122.

WaLdman, R. H. AND GANGULY, R. 1974. Immunity to infections on secretory surfaces. Journal of Infectious Diseases, 130, 419-440. 